\title{
Hypokalemia-induced rhabdomyolysis as the first symptom of primary aldosteronism: a case report and literature review
}

\author{
Rongfeng Han, Xia Jiang \\ Department of Endocrinology, Tianjin First Center Hospital, Tianjin, China \\ Correspondence to: Rongfeng Han. Department of Endocrinology, Tianjin First Center Hospital, Tianjin 300192, China. Email: hanmenghappy@126.com.
}

\begin{abstract}
Primary aldosteronism (PA) is a well-documented cause of secondary hypertension, often accompanied by hypokalemia. However, PA with normal blood pressure and hypokalemic rhabdomyolysis $(\mathrm{RM})$ is rare. We report a case of hypokalemia-induced RM as the first symptom of PA. A 65-year-old woman was admitted due to intermittent limb weakness and myalgia. She denied a history of hypertension. Laboratory findings showed profound hypokalemia $(1.8 \mathrm{mmol} / \mathrm{L})$ and extreme elevation of creatinine kinase (CK) levels (18,370 U/L), suggestive of hypokalemia-induced RM. She was administered intravenous fluids as well as active oral and intravenous potassium supplements. CK and myoglobin levels gradually decreased, but the serum potassium recovery was poor. Further evaluations strongly suggested PA by an aldosteroneproducing adenoma, which was surgically removed. After surgery, the patient recovered well. The systolic blood pressure decreased by approximately $10-20 \mathrm{mmHg}$ and the diastolic blood pressure decreased by approximately 5-10 $\mathrm{mmHg}$. After discontinuation of spironolactone and oral potassium supplementation, the patient had normal serum potassium levels. This case indicates that PA is a cause of hypokalemic RM, even in patients with normal blood pressure. In addition, attention should be paid to changes in serum aminotransferase levels associated with RM. If the patient had no liver disease, it might be a marker for skeletal muscle injury instead of hepatocyte damage.
\end{abstract}

Keywords: Primary aldosteronism (PA); rhabdomyolysis (RM); hypokalemia; aminotransferase; case report

Submitted Oct 17, 2021. Accepted for publication Dec 29, 2021.

doi: 10.21037/apm-21-3010

View this article at: https://dx.doi.org/10.21037/apm-21-3010

\section{Introduction}

Rhabdomyolysis (RM) is a disorder characterized by acute damage of the skeletal muscle, which leads to the release of potentially toxic muscle cell components into the circulation, most notably creatinine kinase (CK) and myoglobin. $\mathrm{RM}$ is a relatively rare and potentially life-threatening condition caused by multiple disorders (1). One of the most interesting causes of RM is potassium deficiency (2). Primary aldosteronism (PA) is a well-documented cause of secondary hypertension resulting from excessive or inappropriately elevated endogenous aldosterone production (3). Cases of PA and hypokalemia are common, but those of RM are rare. Here, we report a very rare case of RM caused by severe hypokalemia, which was, in turn, caused by PA. We present the following case in accordance with the CARE reporting checklist (available at https://apm. amegroups.com/article/view/10.21037/apm-21-3010/rc).

\section{Case presentation}

All procedures performed in this study were in accordance with the ethical standards of the institutional and/or national research committee(s) and with the Helsinki Declaration (as revised in 2013). Written informed consent was obtained from the patient for the publication of this case report and accompanying images. A copy of the written consent is available for review by the editorial office of this journal.

A 65 -year-old female patient visited the clinic due to "intermittent limb weakness for more than 2 months and myalgia for 3 days", and was admitted to the hospital for 
Table 1 Laboratory investigations of the patient

\begin{tabular}{|c|c|c|}
\hline Parameter & Test value & Reference \\
\hline \multicolumn{3}{|l|}{ Biochemistry } \\
\hline Alb (g/L) & 44.7 & $40-55$ \\
\hline BUN (mmol/L) & 1.65 & $3.1-8.8$ \\
\hline Cre $(\mu \mathrm{mol} / \mathrm{L})$ & 59 & $45-84$ \\
\hline $\mathrm{UA}(\mu \mathrm{mol} / \mathrm{L})$ & 425.1 & $155-357$ \\
\hline AST (U/L) & 282 & $13-35$ \\
\hline ALT (U/L) & 90.8 & $7-40$ \\
\hline$\gamma-\mathrm{GT}(\mathrm{U} / \mathrm{L})$ & 13 & $7-45$ \\
\hline T-BIL ( $\mu \mathrm{mol} / \mathrm{L})$ & 24.6 & $0-26$ \\
\hline LDH (U/L) & $1,106.1$ & $120-250$ \\
\hline Myoglobin (ng/mL) & $1,898.7$ & $14.3-65.8$ \\
\hline CK (U/L) & 18,370 & 40-200 \\
\hline CK-MB (ng/mL) & 8.9 & $0.6-6.3$ \\
\hline T-chol (mmol/L) & 5.11 & $0-6.22$ \\
\hline TG (mmol/L) & 2.35 & $0-1.7$ \\
\hline HDL-c (mmol/L) & 0.97 & $1.03-1.55$ \\
\hline LDL-c (mmol/L) & 3.73 & $2.70-3.37$ \\
\hline $\mathrm{Na}(\mathrm{mmol} / \mathrm{L})$ & 144.9 & $137-147$ \\
\hline $\mathrm{K}(\mathrm{mmol} / \mathrm{L})$ & 1.8 & $3.5-5.3$ \\
\hline $\mathrm{Ca}(\mathrm{mmol} / \mathrm{L})$ & 1.93 & $2.11-2.52$ \\
\hline \multicolumn{3}{|l|}{ Hematology } \\
\hline WBC $\left(\times 10^{9} / L\right)$ & 6.92 & $3.5-9.5$ \\
\hline $\operatorname{RBC}\left(\times 10^{9} / \mathrm{L}\right)$ & 4.35 & $3.8-5.1$ \\
\hline HGB (g/L) & 142 & $115-150$ \\
\hline PLT $\left(\times 10^{9} / \mathrm{L}\right)$ & 231 & $125-350$ \\
\hline \multicolumn{3}{|l|}{ Endocrinology } \\
\hline FT3 (pmol/L) & 4.68 & $3.1-6.8$ \\
\hline FT4 (pmol/L) & 19.69 & $12-22$ \\
\hline TSH (mlU/L) & 3.08 & $0.27-4.20$ \\
\hline ACTH (pg/mL) & 10.948 & $7-64$ \\
\hline 8 am cortisol $(\mu \mathrm{g} / \mathrm{dL})$ & 10.445 & $4.26-24.85$ \\
\hline $4 \mathrm{pm}$ cortisol $(\mu \mathrm{g} / \mathrm{dL})$ & 6.705 & $2.9-17.3$ \\
\hline 0 am cortisol $(\mu \mathrm{g} / \mathrm{dL})$ & 4.057 & $0-6.72$ \\
\hline
\end{tabular}

Table 1 (continued)
Table 1 (continued)

\begin{tabular}{lcc}
\hline Parameter & Test value & Reference \\
Urinalysis & 7 & \\
$\mathrm{PH}$ & $2+$ & $4.5-8.0$ \\
Protein & 19.8 & Negative \\
$\mathrm{RBC}(/ \mu \mathrm{L})$ & $0-30.7$ \\
WBC $(/ \mu \mathrm{L})$ & 20.4 & $0-39$ \\
$\begin{array}{l}\text { Urinary cortisol } \\
\text { ( } \mu \mathrm{g} / 24 \mathrm{~h})\end{array}$ & 92.537 & $58-403$ \\
Urine sodium $(\mathrm{mmol} / \mathrm{L})$ & 63 & - \\
$\begin{array}{l}\text { Urine potassium } \\
\text { (mmol/ L) }\end{array}$ & 43.05 & - \\
\hline
\end{tabular}

Alb, albumin; BUN, blood urea nitrogen; Cre, creatinine; UA, uric acid; AST, aspartate aminotransferase; ALT, alanine aminotransferase; $\gamma$-GT, gamma-glutamyltranspeptidase; T-BIL, total bilirubin; $\mathrm{LDH}$, lactate dehydrogenase; CK, creatinine kinase; CK-MB, creatine kinase isoenzymes; T-chol, total cholesterol; TG, triglyceride; HDL-c, high-density lipoprotein cholesterol; LDL-c, low-density lipoprotein cholesterol; WBC, white blood cell; RBC, red blood cell; HGB, hemoglobin; PLT, platelet count; FT3, free triiodothyronine; FT4, free thyroxine; $\mathrm{TSH}$, thyrotropin; ACTH, adrenocorticotropic hormone; RBC, red blood cell.

"hypokalemia" upon serum potassium test $(1.8 \mathrm{mmol} / \mathrm{L})$. She had no history of medication use and denied a history of hypertension, coronary heart disease, diabetes mellitus, thyroid disease, or other diseases. Physical examination on admission revealed no obvious abnormality in the heart, lung, or abdomen; mild muscle tenderness in the limbs; grade V muscle strength of the upper limbs; and grade IV lower limb muscle strength and normal limb muscle tone. The patient's blood pressure was measured twice a day during hospitalization, but no hypertension was detected. The blood pressure monitored after admission fluctuated within $120-138 / 70-87 \mathrm{mmHg}$. The laboratory evaluations are shown in Table 1 . The serum potassium was $1.8 \mathrm{mmol} / \mathrm{L}$, CK was $18,370 \mathrm{IU} / \mathrm{L}$, myoglobin was $1,898.7 \mathrm{ng} / \mathrm{mL}$, aspartate aminotransferase (AST) was $282 \mathrm{IU} / \mathrm{L}$, and alanine aminotransferase (ALT) was $90.8 \mathrm{IU} / \mathrm{L}$. Blood urea nitrogen (BUN) and creatinine levels were normal. Arterial blood gas analysis revealed metabolic alkalosis (pH 7.55; $\mathrm{PaCO}_{2} 47.4$ mmHg; $\mathrm{HCO}_{3} 41.2$; base excess 
Table 2 Preoperative and postoperative standard posture test of the renin-angiotensin-aldosterone system

\begin{tabular}{|c|c|c|c|c|c|c|}
\hline Hormones & Preoperative supine & $\begin{array}{l}\text { Postoperative } \\
\text { supine }\end{array}$ & Reference (supine) & $\begin{array}{c}\text { Preoperative } \\
\text { upright }\end{array}$ & $\begin{array}{c}\text { Postoperative } \\
\text { upright }\end{array}$ & Reference (upright) \\
\hline PRA (pg/mL) & 6.566 & 15.181 & $4-24$ & 4.204 & 31.614 & $4-38$ \\
\hline PAC (pg/mL) & $>1,000$ & 79.253 & $10-160$ & $>1,000$ & 83.073 & $40-310$ \\
\hline
\end{tabular}

PRA, plasma renin activity; ANG II, angiotensin II; PAC, plasma aldosterone concentration.

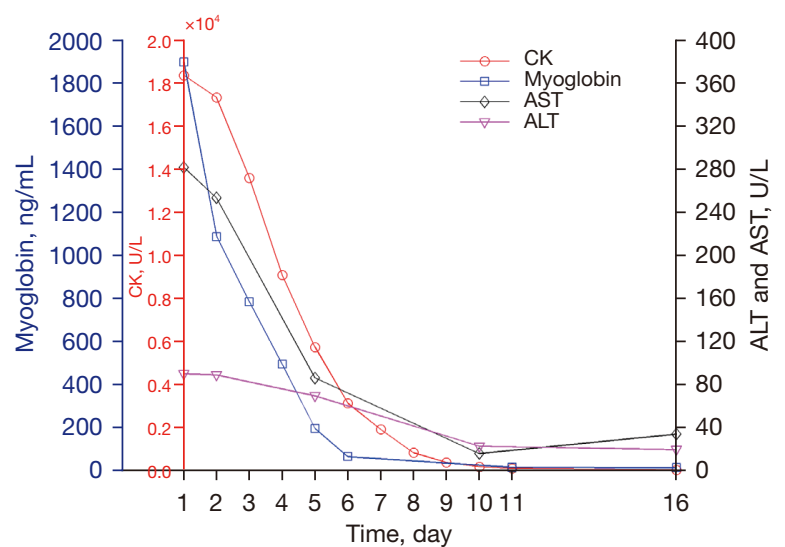

Figure 1 The change curves of CK, myoglobin, AST, and ALT. CK, creatine kinase; AST, aspartate aminotransferase; ALT, alanine transaminase.

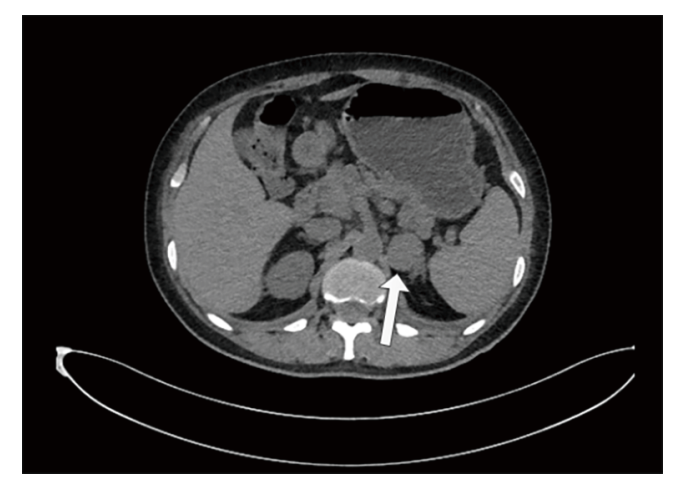

Figure 2 Abdominal computed tomography showed a $2.8 \mathrm{~cm}$ $\times 2.6 \mathrm{~cm}$ nodule in the left adrenal gland (arrow).

$16.9 \mathrm{mmol} / \mathrm{L}$ ). Based on the above findings, the patient was diagnosed with hypokalemic RM. She was administered intravenous fluids as well as active oral and intravenous potassium supplements. CK and myoglobin levels gradually decreased, but the serum potassium recovery was poor. Based on the results of the standard posture test of the

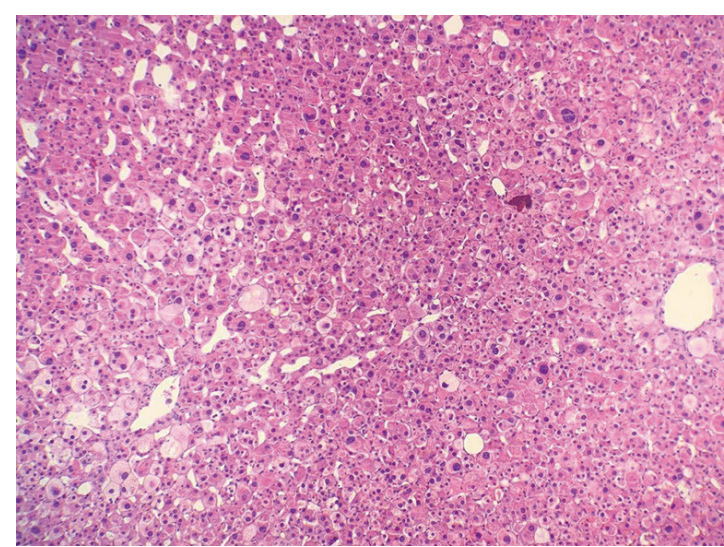

Figure 3 The light-microscopic observation revealed that the resected specimen was histopathologically consistent with the diagnosis of adenoma. H\&E staining, 200× magnification. H\&E, hematoxylin and eosin.

renin-angiotensin-aldosterone system (Table 2), the patient was administered spironolactone. The serum potassium level returned to the normal range. After treatment, the CK, myoglobin, AST, and ALT levels gradually decreased to normal levels (Figure 1). Upon repeated examination, no abnormalities were observed in the BUN and creatinine levels. The patient's muscular weakness and myalgia resolved. Computed tomography of the abdomen revealed a nodule in the left adrenal gland (Figure 2). She visited the Urology Department for "adrenal occupying lesion and primary aldosteronism", and underwent laparoscopic left adrenalectomy. During the operation, a tumor with a diameter of approximately $3 \mathrm{~cm}$ was observed. The mass was spherical and occupied the middle of the adrenal gland. Her blood pressure was intraoperatively stable, and the operation went smoothly. The postoperative pathological diagnosis was adrenocortical adenoma (Figure 3). After removal of the adrenal adenoma, the systolic blood pressure decreased by approximately $10-20 \mathrm{mmHg}$ and 
Table 3 The patients with PA and RM in China

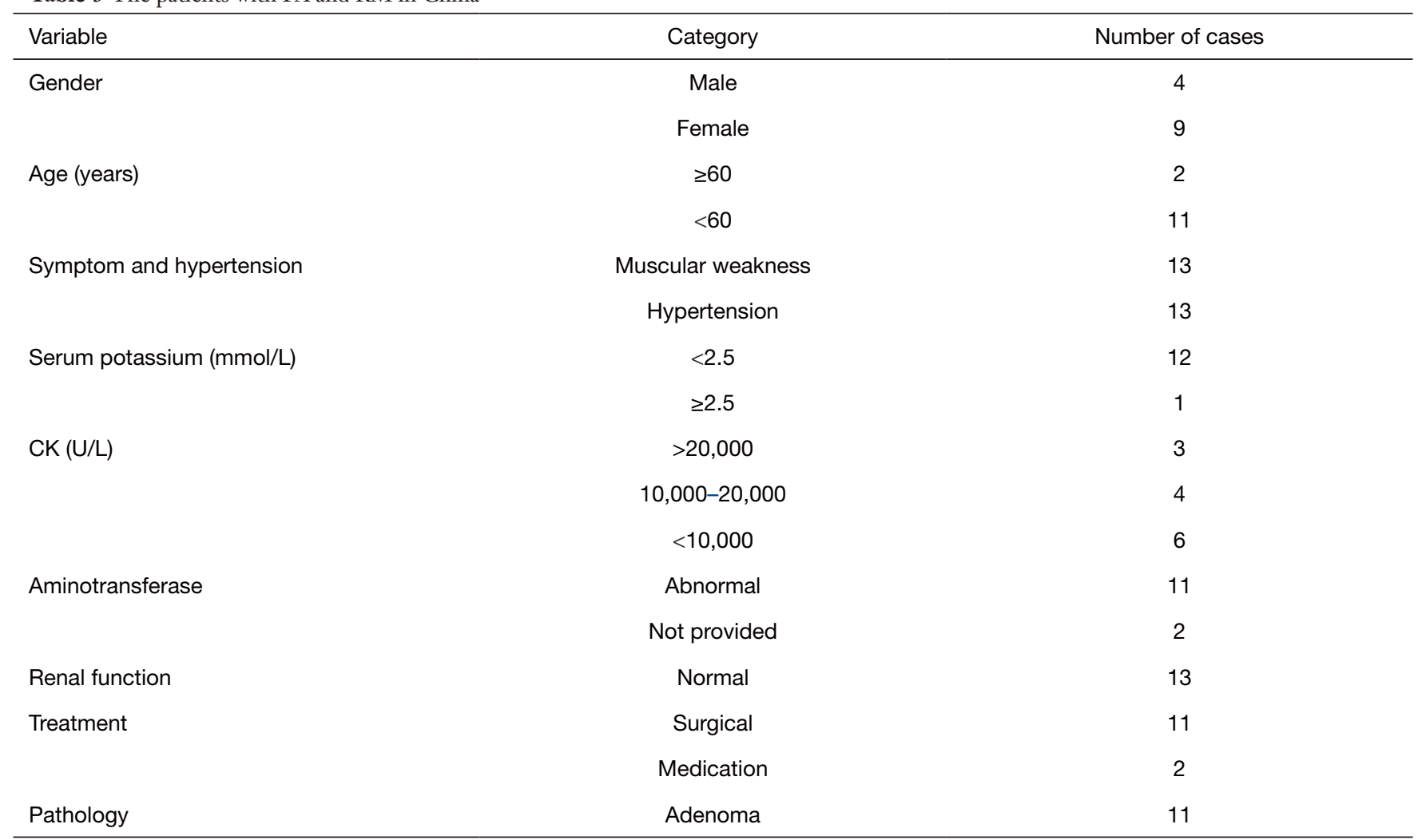

PA, primary aldosteronism; RM, rhabdomyolysis; CK, creatinine kinase.

the diastolic blood pressure decreased by approximately 5-10 $\mathrm{mmHg}$ compared to the values that would have been obtained without spironolactone. Unfortunately, we did not conduct continuous 24-hour ambulatory blood pressure monitoring and did not observe dynamic blood pressure changes. Postoperatively, the patient recovered well. After discontinuation of spironolactone and oral potassium supplementation, the patient had normal serum potassium levels. The standard posture test of the renin-angiotensinaldosterone system was normal (Table 2).

\section{Discussion}

$\mathrm{RM}$ is a syndrome characterized by muscle necrosis and myocyte content release into the circulation, which significantly increases CK, often more than 10 times higher than the normal upper limit (4). Patients with mild symptoms may have asymptomatic elevated CK only, and those with severe symptoms may develop acute heart failure, respiratory distress syndrome, gastrointestinal hemorrhage, metabolic acidosis, hypovolemic shock, acute renal failure
(ARF), disseminated intravascular coagulation (DIC), and multiple organ failure (5). There are many etiologies of RM, which can be divided into physical and non-physical causes of muscle injury. Physical factors include strenuous exercise, crush syndrome, and burns. Non-physical factors include drugs, toxicants, infections, and metabolic disorders (6). PA is characterized by the overproduction of aldosterone by the adrenal cortex. Aldosterone influences the cardiovascular system by increasing sodium retention, enlarging blood volume, and inhibiting the renin-angiotensin system. Common manifestations of PA include hypertension and hypokalemia. PA can induce excessive potassium excretion, which causes, under extreme conditions, RM (7).

In the Chinese biomedical literature database, 13 cases have been reported of PA being related to hypokalemic RM (Table 3); four of the patients were male and nine were female; and two were over the age of 60 and 11 were younger than 60 years old. All 13 patients had a history of hypertension and weakness. Twelve patients had blood potassium less than $2.5 \mathrm{mmol} / \mathrm{L}, 1$ had blood potassium greater than $2.5 \mathrm{mmol} / \mathrm{L}, 11$ had adrenal adenoma, and 
none had renal failure. Zavatto et al. (8) summarized 22 cases of PA related to hypokalemic RM in the English literature. Among the cases, 9 patients were male and 13 were female, 5 were 60 years old or older and 17 were younger, 21 had symptoms of fatigue, and 20 had hypertension. Only one patient had a blood potassium greater than $2.5 \mathrm{mmol} / \mathrm{L}$, 17 had adrenal adenoma, and 3 had renal failure. The mechanism of hypokalemia-induced RM is still not clear, but it may be related to the fact that hypokalemia may induce (I) contraction of capillaries, which reduces muscle blood supply, resulting in muscle cell destruction; (II) suppression of synthesis and storage of glycogen; and (III) deranged ion transport across the cell membrane (8). Not all patients with PA and hypokalemia develop RM, an outcome possibly related to extent of hypokalemia. In the cases summarized in this paper, only one patient had a serum potassium higher than $2.5 \mathrm{mmol} / \mathrm{L}$. This was possibly related to the potassium supplement consumed outside the hospital. Therefore, when severe hypokalemia, defined as a serum potassium $<2.5 \mathrm{mmol} / \mathrm{L}$, is detected, we should be aware of the possibility of RM development. In patients with RM caused by hypokalemia, if hypokalemia is not detected and corrected early, it can further aggravate muscle damage. The severity of RM syndrome caused by hypokalemia and its prognosis are related to the degree of pre-existing potassium deficiency and the underlying disease state (9). In addition, when diuretics were selected for antihypertensive treatment, serum potassium levels should be monitored to avoid RM.

The elderly female patient presented mainly with weakness and myalgia. The CK level was 18,370 U/L, and the minimum serum potassium was $1.8 \mathrm{mmol} / \mathrm{L}$. Considering that RM is caused by severe hypokalemia, it is necessary to actively correct it and closely monitor blood potassium levels. After the patient was given full fluid infusion and potassium supplementation, CK and myoglobin were favorably reduced, while hypokalemia was difficult to completely correct. This indicates the possibility of obvious potassium loss. Therefore, it is necessary to further improve the examination to identify the cause of hypokalemia. Based on relevant laboratory examinations, the patient suffered from PA. After administration of an aldosterone inhibitor (spironolactone), serum potassium rapidly returned to normal levels. Therefore, hypokalemiainduced RM might be a herald of PA. The patient denied a history of hypertension, and monitoring of blood pressure after admission revealed no elevation of blood pressure. This is an important feature of the case reported in this article. Vantyghem et al. (10) reported that blood pressure decreased after aldosterone-producing adenoma resection in non-hypertensive patients, suggesting that hyperaldosteronism was responsible for relative hypertension; however, the blood pressure remained at non-hypertensive levels due to low spontaneous baseline levels. The blood pressure of the patients in our reported case also dropped compared to the levels measured before the operation, which is similar to a previous report. Nonhypertensive PA is extremely rare. Many cases are middleaged Eurasian (especially Japanese) women, which suggests that genetic and gender-related protective factors may play a role in the response to excess aldosterone. The prevalence of PA with normal blood pressure may be underestimated because PA is almost never screened for in normotensive patients without hypokalemia or adrenal masses (11).

Of the 13 patients whose cases are summarized in this paper, 11 patients received surgical treatment, with the postoperative pathology being adrenal adenoma, and the other 2 patients received drug therapy. In addition, attention should be paid to serum aminotransferase changes associated with RM. Elevation of aminotransferase to varying degrees was observed in the case discussed in this paper and in cases with previous liver function reports (Table 3). The elderly female patient was excluded from the aminotransferase abnormality caused by viral hepatitis, fatty liver, drug, or autoimmune disease. Serum aminotransferase is also present in the skeletal muscle. Several studies have reported that the change in serum AST and ALT is correlated with the CK level, which suggests that elevated aminotransferase in RM might be a marker for skeletal muscle injury instead of hepatocyte damage (12-15).

Clinically, if hypokalemia-induced RM is present, the cause of hypokalemia should be actively determined. If $\mathrm{RM}$ is caused by severe hypokalemia due to PA, the effect of pure potassium supplementation will be poor, and the treatment should focus on inhibiting urinary potassium loss. In addition, during correction of hypokalemia, special attention should be paid to monitoring serum potassium levels. RM causes the release of large amounts of potassium into the circulation. This may lead to fatal hyperkalemia (16). Acute renal failure is the most common severe complication of RM. Interestingly, no acute renal failure was observed in this patient and the previous cases summarized in this paper, possibly due to (I) plenty of liquid infusion in the treatment, with circulating blood volume sufficient for renal perfusion maintenance, and (II) alkaline urine promoting myoglobin discharge at low potassium levels. 
Hypokalemia-induced RM is not common in PA but is life-threatening without timely treatment. Therefore, during active symptomatic treatment, we should determine the causes and closely monitor the CK, electrolyte, aminotransferase, creatinine, etc. Meanwhile, we should be alert to acute renal failure and manage with the goal of avoiding related complications. Patients may be administered mineralocorticoid receptor antagonists (e.g., spironolactone) or may undergo laparoscopic adrenalectomy for the treatment of primary disease. In addition, the change in serum aminotransferase levels correlated with the CK level might be a marker for muscle injury instead of hepatocyte damage.

\section{Conclusions}

This case indicates that PA is a cause of hypokalemic RM, even in normotensive patients. In addition, attention should be paid to serum aminotransferase changes associated with RM. If the patient had no liver disease, it might be a marker for skeletal muscle injury instead of hepatocyte damage.

\section{Acknowledgments}

Funding: None.

\section{Footnote}

Reporting Checklist: The authors have completed the CARE reporting checklist. Available at https://apm.amegroups. com/article/view/10.21037/apm-21-3010/rc

Conflicts of Interest: Both authors have completed the ICMJE uniform disclosure form (available at https://apm. amegroups.com/article/view/10.21037/apm-21-3010/coif). The authors have no conflicts of interest to declare.

Ethical Statement: The authors are accountable for all aspects of the work in ensuring that questions related to the accuracy or integrity of any part of the work are appropriately investigated and resolved. All procedures performed in this study were in accordance with the ethical standards of the institutional and/or national research committee(s) and with the Helsinki Declaration (as revised in 2013). Written informed consent was obtained from the patient for publication of this case report and accompanying images. A copy of the written consent is available for review by the editorial office of this journal.
Open Access Statement: This is an Open Access article distributed in accordance with the Creative Commons Attribution-NonCommercial-NoDerivs 4.0 International License (CC BY-NC-ND 4.0), which permits the noncommercial replication and distribution of the article with the strict proviso that no changes or edits are made and the original work is properly cited (including links to both the formal publication through the relevant DOI and the license). See: https://creativecommons.org/licenses/by-nc-nd/4.0/.

\section{References}

1. Goto A, Takahashi Y, Kishimoto M, et al. Primary aldosteronism associated with severe rhabdomyolysis due to profound hypokalemia. Intern Med 2009;48:219-23.

2. Jung YL, Kang JY. Rhabdomyolysis following severe hypokalemia caused by familial hypokalemic periodic paralysis. World J Clin Cases 2017;5:56-60.

3. Stowasser M. Update in primary aldosteronism. J Clin Endocrinol Metab 2015;100:1-10.

4. Zutt R, van der Kooi AJ, Linthorst GE, et al. Rhabdomyolysis: review of the literature. Neuromuscul Disord 2014;24:651-9.

5. Khan FY. Rhabdomyolysis: a review of the literature. Neth J Med 2009;67:272-83.

6. Qiao H, Cheng H, Liu L, et al. Potential factors involved in the causation of rhabdomyolysis following status asthmaticus. Allergy Asthma Clin Immunol 2016;12:43.

7. Lee JH, Kim E, Chon S. Hypokalemia-induced rhabdomyolysis by primary aldosteronism coexistent with sporadic inclusion body Myositis. Ann Rehabil Med 2015;39:826-32.

8. Zavatto A, Concistrè A, Marinelli C, et al. Hypokalemic rhabdomyolysis: a rare manifestation of primary aldosteronism. Eur Rev Med Pharmacol Sci 2015;19:3910-6.

9. Allison RC, Bedsole DL. The other medical causes of rhabdomyolysis. Am J Med Sci 2003;326:79-88.

10. Vantyghem MC, Ronci N, Provost F, et al. Aldosteroneproducing adenoma without hypertension: a report of two cases. Eur J Endocrinol 1999;141:279-85.

11. Ito Y, Takeda R, Karashima S, et al. Prevalence of primary aldosteronism among prehypertensive and stage 1 hypertensive subjects. Hypertens Res 2011;34:98-102.

12. Jo KM, Heo NY, Park SH, et al. Serum aminotransferase level in rhabdomyolysis according to concurrent liver disease. Korean J Gastroenterol 2019;74:205-11.

13. Lee GY, Lee H, Kim YJ. Rhabdomyolysis recognized after 
elevation of liver enzymes following prolonged urologic surgery with lateral decubitus position -A case report-. Korean J Anesthesiol 2011;61:341-3.

14. Nathwani RA, Pais S, Reynolds TB, et al. Serum alanine aminotransferase in skeletal muscle diseases. Hepatology 2005;41:380-2.

15. Weibrecht K, Dayno M, Darling C, et al. Liver

Cite this article as: Han R, Jiang X. Hypokalemia-induced rhabdomyolysis as the first symptom of primary aldosteronism: a case report and literature review. Ann Palliat Med 2022;11(8):2778-2784. doi: 10.21037/apm-21-3010 aminotransferases are elevated with rhabdomyolysis in the absence of significant liver injury. J Med Toxicol 2010;6:294-300.

16. Chatzizisis YS, Misirli G, Hatzitolios AI, et al. The syndrome of rhabdomyolysis: complications and treatment. Eur J Intern Med 2008;19:568-74. 